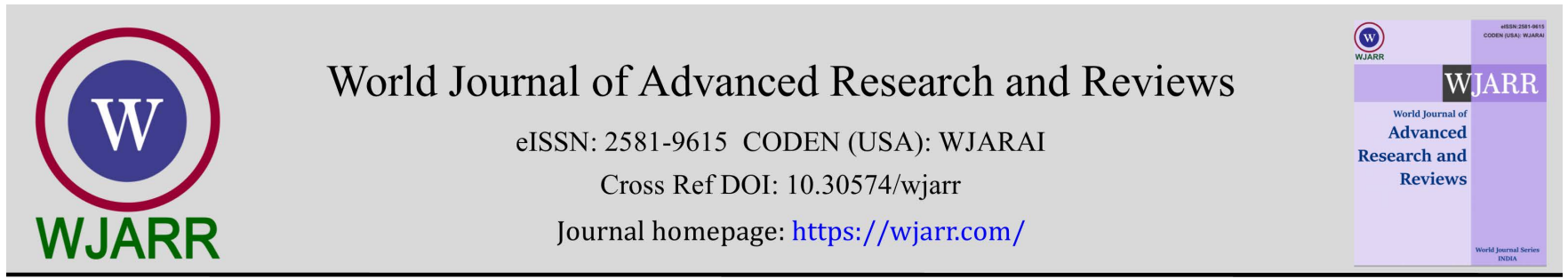

(RESEARCH ARTiClE)

Check for updates

\title{
Evaluation of the hypolipidemic effect of Gangaria de flush herbal mixture in streptozotocin-induced diabetic male rats
}

\author{
Babafemi Tosin Ogunbiyi 1, ${ }^{*}$, Gogonte Hezekiah Amah ${ }^{1}$, Laide Omoyiola Olajide 1, Olubunmi Esther \\ Ogunbiyi ${ }^{2}$, Oluwafunmilola Christiana Adetunji ${ }^{1}$, Modupe Olusola Adetayo ${ }^{1}$ and Oluwaseyi Olagoke \\ Adetunji 1 \\ ${ }^{1}$ Department of Biochemistry, School of Basic Medical Sciences, Babcock University, Ilishan-Remo, Ogun State, Nigeria.
${ }^{2}$ Department of Anatomy, School of Basic Medical Sciences, Babcock University, Ilishan-Remo, Ogun State, Nigeria.
}

World Journal of Advanced Research and Reviews, 2021, 11(03), 066-071

Publication history: Received on 31 July 2021; revised on 02 September 2021; accepted on 04 September 2021

Article DOI: https://doi.org/10.30574/wjarr.2021.11.3.0423

\begin{abstract}
Diabetes mellitus is a complex multifarious metabolic disorder characterized by chronic hyperglycemia that requires non-stop treatment with multiple factors that will reduce the risk of long-term complications and drug side effects. Streptozotocin is well known for its selective pancreatic islet $\beta$-cell cytotoxicity used to induce diabetes mellitus in animals. It also interferes with cellular metabolic oxidative mechanisms. Phytomedicine has been in existence since the primitive age and has proven to be effective in treating this condition. This study was aimed at evaluating the effect of Gangaria de flush (Gdf) herbal mixture on lipid profile in streptozotocin (STZ) $(60 \mathrm{mg} / \mathrm{kg}$ ) induced diabetic rat. The diabetic rats were treated with Gangaria de flush $(0.3 \mathrm{ml} / \mathrm{kg}$ body weight) and Glibenclamide ( $5 \mathrm{mg} / \mathrm{kg}$ body weight) for 7 days. The effects of both Gangaria de flush herbal mixture and glibenclamide were analyzed. Gangaria de flush showed a reduction in the lipid profile with a significant percentage reduction of $45.9 \%$ for the total cholesterol, $65.7 \%$ for the total triglyceride, $63.5 \%$ for the low-density lipoprotein, $65.8 \%$ for the very low-density lipoprotein as against the negative control and a 7.6\% significant increase in the high density lipoprotein. Gangaria de flush showed a significant $(\mathrm{p}<0.05)$ positive effect on the lipid profile. Hence, it can be suggested that Gangaria de flush herbal mixture has a significant effect in maintaining the lipid level.
\end{abstract}

Keywords: Lipid profile; Gangaria de Flush; Diabetes Mellitus; Streptozotocin; Phytomedicine

\section{Introduction}

Diabetes mellitus is a complex multifarious group of disorders that disturbs the metabolism of carbohydrates, fats and proteins. It results from shortage or lack of insulin secretion or reduced sensitivity of the tissue to insulin. It increases risk of cardiovascular diseases complications [1]. The two forms of diabetes, type 1 and 2, differ in their basic mechanisms of development and in physiologic characteristics such as associations with obesity, age, and insulin. But, both types of the diabetes share the common characteristics of hyperglycemia, microvascular and macrovascular complications. Moreover, the alterations of lipoproteins metabolism are involved to the pathogenesis of the cardiovascular disease in both forms of diabetes in a similar way [2]. Also, diabetes is usually accompanied by increased generation of free radicals or impaired antioxidant defenses. Oxidative stress is also responsible for the development and progression of diabetes and its complications are reported by Maritim et al. [3].

Several drugs such as biguanides and Sulfonylureas are currently available to reduce hyperglycemia [4]. These drugs have proven to have side effect and thus the search for new therapeutic compound is essential to overcome the diabetic

\footnotetext{
* Corresponding author: Babafemi Tosin Ogunbiyi

Department of Biochemistry, School of Basic Medical Sciences, Babcock University, Ilishan-Remo, Ogun State, Nigeria

Copyright (c) 2021 Author(s) retain the copyright of this article. This article is published under the terms of the Creative Commons Attribution Liscense 4.0.
} 
problems [5]. The management of diabetes without side effect is still a challenge to the medical society. Therefore, it is advisable to look for options in alternative medicine or herbals for diabetes as well. Although, herbal medicines have long been used effectively in treating disease in Africa, Asian communities and throughout the world, yet most of the herbal mixtures used have not been scientifically defined [6].

It has been attributed that the hypoglycemic effect of these herbal mixtures from plants is due to their ability to restore the function of pancreatic cell hence causing an increase in insulin production, facilitation of metabolites in insulindependent process or inhibiting the intestinal absorption of glucose. Hence, treatment with herbal drugs has an effect on protecting cells and smoothing out fluctuation in glucose levels $[7,8]$. Most of the plants have been found to contain active components like glycosides, alkaloids, terpenoids, and flavonoids. Herbal medicine has shown to play a major role in modern medicine. The origin has been traced back to the primitive age and as greatly evolved into a diverse therapeutic agent. Herbal medicine is currently tagged under Traditional African Medicine (TAM), a WHO initiative set up to review the growth in consumption of plant and natural based drugs due to the increasing trend in the three quarter of Africans that rely on herbal medicine has reported by World Health Organization (WHO) [9].

The elevation of serum total cholesterol, triglycerides and low density lipoproteinl (LDL) along with decreased HDL levels are known to cause hyperlipidemia which is responsible for initiation and progression of atherosclerosis impasse [10].

Gangaria de flush (Gdf) herbal mixture is a widely used herbal mixture due to its known tradomedicinal efficacy. Gangaria de flush is a polyherbal mixture which comprises of Dolichos lablab (kidney bean) (Fruit- 5\%), Khaya grandifolia (African mahogany) (Bark-15\%), Securida calongepedunculata- (mufufu) (Bark-15\%), Citrullus colocynthis (Bitter apple) (Fruit-15\%), Chrysophyllum albidum (White star apple) (Tuber- 15\%), Curciligo pilosa (African crocus) (Tuber-15\%) and Sorghum caudatum (millet) (Leaves- 20\%). This mixture was specifically formulated for the management of pile and all associated pain in the body system, evacuation of all accrued waste pain, strengthen erection, management of fibroid \& menstrual cycle disorder and acts as an immune system booster. The characteristic healing effect of this herbal mixture have not been researched, and also the mechanism of action has not been well understood. Thus, this present study was undertaken to evaluate the hypolipidemic effect of GdF herbal mixture in streptozotocininduced diabetic male rats.

\section{Material and methods}

\subsection{Herbal preparation}

Gangaria de flush was manufactured by Sary Salam Herbal Commercial Nigeria Enterprises and purchased from one of the company's mobile suppliers in Ilishan-Remo, Ogun State, Nigeria.

\subsection{Experimental animals and experimental conditions}

Twenty (20) adults male Wistar rats were obtained with an initial average weight of 150-250 g, from the Animal facility, Babcock University, Ilishan Remo, Ogun State. The animals were maintained in individual cages at a room temperature of $25 \pm 3^{\circ} \mathrm{C}$ in a $12 \mathrm{~h}$ light/dark cycle and with access to food and water ad libitum for two weeks. This protocol was examined and approved by Babcock University Health Research Ethics Committee, Ilishan Remo, Ogun State.

\subsubsection{Induction of experimental diabetes in rats}

The animals were randomly divided into four groups; Normal Control, Negative control, Positive control, and Test Group, with five animals in each group. Streptozotocin (STZ) was dissolved in freshly prepared $0.1 \mathrm{M}$ cold citrate buffer (pH 4.5). The animals in the positive control group, negative control group and Test group were subjected to overnight fasting and received $60 \mathrm{mg} / \mathrm{kg}$ body weight STZ via intraperitoneal route [11]. After 6 hours of STZ administration, the rats received 5\% dextrose solution for the next 24 hours to prevent STZ induced fatal hypoglycemia as a result of massive pancreatic insulin release after its administration [12]. The measurement of tail vein blood glucose level was done using a glucometer (Accu Check). Diabetic rats were kept for 4 days under standard laboratory condition for the stabilization of blood glucose levels. Afterwards, the blood glucose level was obtained and animals with blood glucose level greater than $250 \mathrm{mg} / \mathrm{dl}$ were selected for the study [13].

\subsubsection{Experimental design for antidiabetic activity}

The rats were divided into four groups with five rats in each group. Group 1: normal control rats received standard rat chow and water; group 2: STZ-induced diabetic rats were without treatment; group 3: STZ-induced diabetic rats were 
treated with glibenclamide $(5 \mathrm{mg} / \mathrm{kg}$ ) bodyweight which was administered orally; group 4: STZ-induced diabetic rats were treated with Gdf herbal mixture $(0.3 \mathrm{ml} / \mathrm{kg})$ body weight administered orally [14]. Gdf herbal mixture and glibenclamide were administered orally to its respective group animals for 7 days. Body weights were estimated every day. At the end of the seventh day, Gdf herbal mixture and glibenclamide were administered to the overnight fasted animals and after $1 \mathrm{~h}$ treatment, all animals were anaesthetized with chloroform [11]. Blood was collected by cardiac puncture into a Lithium Heparin sample tubes for biochemical investigations involving lipid profiles. The serum portion of the blood was separated after centrifuging at 4,000 rpm at room temperature for 15 minutes. The remains of the animals were placed in a disposable bag and buried at a distant of $2 \mathrm{ft}$ at a secluded area reserved for the purpose at the animal facility.

\subsubsection{Estimation of biochemical parameters}

The serum lipid profiles; high density lipoprotein (HDL), total cholesterol (TC) and triglycerides (TG) was estimated using commercially available kits. The serum low density lipoprotein (LDL) and very low-density lipoprotein (VLDL) levels were estimated using the equation from Sampson et al. [15].

$$
\begin{gathered}
\text { VLDL-C }=\mathrm{TG} / 8.59+\{(\mathrm{TG} \times \text { Non-HDL-C }) / 2250\}-\left(\mathrm{TG}^{2} / 16500\right) \\
\text { LDL-C }=\mathrm{TC} / 0.948-\mathrm{HDL}-\mathrm{C} / 0.971-\left\{(\mathrm{TG} / 8.56)+((\mathrm{TG} \times \mathrm{Non}-\mathrm{HDL}-\mathrm{C}) / 2140)-\left(\mathrm{TG}^{2} / 16100\right)\right\}-9.44 .
\end{gathered}
$$

\subsection{Statistical analysis}

Data were expressed as mean \pm standard error of mean $(\mathrm{SEM})(\mathrm{n}=5)$. Statistical evaluation of data was performed by GraphPad Prism ${ }^{\circledR}$ version 7.0 using one-way analysis of variance (ANOVA), followed by Duncan's post-hoc analysis for multiple comparison. Values were considered statistically different at $p<0.05$.

\section{Results}

Table 1 Body Weight of the experimental groups represented as mean \pm SEM

\begin{tabular}{|l|c|c|c|c|}
\hline \multirow{2}{*}{ Groups } & \multicolumn{4}{|c|}{ body weight (grams) } \\
\cline { 2 - 5 } & $\mathbf{0 ~ d a y}$ & $\mathbf{1}$ day & 4days & $\mathbf{7}$ days \\
\hline Normal & $171.3 \pm 5.9$ & $170.9 \pm 5.8$ & $180.4 \pm 7.2$ & $184.6 \pm 6.7$ \\
\hline Diabetic without treatment & $196.3 \pm 10.2^{\mathrm{a}}$ & $196.3 \pm 10.2^{\mathrm{a}}$ & $156.3 \pm 13.2^{\mathrm{a}}$ & $163.7 \pm 13.5^{\mathrm{a}}$ \\
\hline Diabetic and treated with glibenclamide 5mg/kg & $196.3 \pm 10.2^{\mathrm{a}}$ & $174 \pm 4.8^{\mathrm{b}}$ & $137.4 \pm 3.8^{\mathrm{a}, \mathrm{b}}$ & $142.3 \pm 6.4^{\mathrm{a}, \mathrm{b}}$ \\
\hline $\begin{array}{l}\text { Diabetic and treated with Gangaria de flush } \\
0.3 \mathrm{ml} / \mathrm{kg}\end{array}$ & $196.3 \pm 10.2^{\mathrm{a}}$ & $184.9 \pm 11.6^{\mathrm{a}, \mathrm{b}}$ & $148.8 \pm 11.9^{\mathrm{a}, \mathrm{b}}$ & $146.5 \pm 16.2^{\mathrm{a}, \mathrm{b}}$ \\
\hline
\end{tabular}

\begin{tabular}{|c|c|c|c|c|c|}
\hline \multirow[t]{2}{*}{ Groups } & \multicolumn{5}{|c|}{ Lipid profile(mg/dL) } \\
\hline & $\begin{array}{l}\text { Total } \\
\text { Cholesterol }\end{array}$ & Triglyceride & $\begin{array}{l}\text { Very Low- } \\
\text { Density } \\
\text { Lipoprotein }\end{array}$ & $\begin{array}{l}\text { Low density } \\
\text { lipoprotein }\end{array}$ & $\begin{array}{l}\text { High Density } \\
\text { Lipoprotein }\end{array}$ \\
\hline Normal & $362.6 \pm 0.04$ & $431.0 \pm 0.05$ & 96.09 & 110.77 & $181.6 \pm 0.01$ \\
\hline $\begin{array}{l}\text { Diabetic } \quad \text { without } \\
\text { treatment }\end{array}$ & $717.1 \pm 0.16^{\mathrm{a}}$ & $1136.5 \pm 0.14^{a}$ & $343.02^{a}$ & $241.35^{a}$ & $146.3 \pm 0.02^{\mathrm{a}}$ \\
\hline $\begin{array}{l}\text { Diabetic and treated } \\
\text { with glibenclamide } \\
5 \mathrm{mg} / \mathrm{kg}\end{array}$ & $463.9 \pm 0.06^{\mathrm{a}, \mathrm{b}}$ & $287.0 \pm 0.02^{\mathrm{a}, \mathrm{b}}$ & $67.40^{\mathrm{b}}$ & $246.63^{\mathrm{a}, \mathrm{b}}$ & $159.2 \pm 0.01^{\mathrm{a}, \mathrm{b}}$ \\
\hline $\begin{array}{l}\text { Diabetic and treated } \\
\text { with Gangaria de flush } \\
0.3 \mathrm{ml} / \mathrm{kg}\end{array}$ & $388.0 \pm 0.03^{\mathrm{a}, \mathrm{b}}$ & $390.0 \pm 0.04^{\mathrm{a}, \mathrm{b}}$ & $76.40^{\mathrm{a}, \mathrm{b}}$ & $160.79 a, b$ & $156.4 \pm 0.01^{\mathrm{a}, \mathrm{b}}$ \\
\hline
\end{tabular}

Table 2 The serum lipid profile of the experimental groups represented as mean \pm SEM 
Data in Table 1 showed that GdF and diclofenac sodium reduced the body weight of the animals daily. The GdF treated group showed a significant $(p<0.05)$ reduction in the body weight as compared also to glibenclamide treated group which also showed a significant $(p<0.05)$ reduction in the body weight. Also, data in Table 2 showed increased serum total cholesterol, triglyceride, LDL-cholesterol and HDL-cholesterol level, and VLDL-cholesterol on administration of STZ to the animals when compared to normal group at over a period of 7 days. Administration of $0.3 \mathrm{~mL} / \mathrm{kg}$ b.w. GdF showed statistically significant decrease $(p<0.05)$ in total cholesterol, triglyceride, LDL-cholesterol, and VLDLcholesterol while increase in HDL-cholesterol level $(p<0.05)$ as compared to the untreated animals.

\section{Discussion}

In this study, the hypolipidemic effect of Gangaria de Flush herbal mixture was evaluated. Streptozotocin (STZ) is a broad-spectrum antibiotic gotten from Streptomyces acromogenes. The induction of diabetes with STZ causes the damage of pancreatic $\beta$-cells of islets, which eventually leads to a reduction of insulin release and elevated glucose in the blood [16].

The increase in diabetic cases and the side effect of few currently used drug has led to the search of new drugs and method of treatment. It has been attributed that the hypoglycemic effect of few herbal mixtures from plants e.g. ginseng gotten from ginger, is due to their ability to restore the function of pancreatic cell hence causing an increase in insulin production, facilitating metabolites in insulin-dependent processes or inhibiting the intestinal absorption of glucose. Also, for the lipid profile, it inhibits the activity of HMG-CoA reductase essential for the biosynthesis of cholesterol and its derivatives. Hence, treatment with herbal drugs has an effect on protecting cells and smoothing out fluctuation in glucose levels [7, 8].

A crucial role is played by lipids in the pathogenesis of diabetic mellitus. Hyperglyceridemia and hypercholesterolemia are the most common lipid abnormalities in diabetes and this may be due to the fact that under normal situations, the hormone insulin stimulates lipoprotein lipase and hydrolyses triglycerides. This increases uptake of fatty acids into adipose tissue and thus increases the synthesis of tryglycerides. Insulin also inhibits lipolysis. In diabetic condition, the deficiency of insulin leads to an elevated lipolytic action, increasing free fatty acid influx from deposited fats, distorting the balance of the free fatty acid esterification-triglyceride lipolysis cycle, which ultimately leads to hyperlipidemia [16].

Diabetes is associated with other diseases especially lipid metabolism defects affecting the plasma lipid and lipoprotein profile. A known pattern or characteristics of hyperlipidemia in patients with diabetes include increased triglycerides, reduced High Density Lipoprotein, increased total cholesterol and Low-Density Lipoprotein. The data from this study showed the various levels of the lipid profile for the different groups of the study. According to Veerapur et al., (2010), the elevated sera levels of lipid profile are responsible for coronary diseases as secondary disorder resulting from diabetes [17]. Results from this study shows that Gdf would be helpful in preventing diabetes related complications by improving the level of lipid profile of the diabetic rat. The on-set of diabetes initiated the elevation of total cholesterol, but a significant percentage decrease was seen in the diabetic groups treated with Glibenclamide and Gdf. A significant percentage reduction was also observed in the total triglyceride level of the diabetic rats when compared to the untreated diabetic rat. A significant percentage reduction was also observed in Low Density Lipoprotein and the Very low-density lipoprotein respectively.

For the High-density lipoprotein, a significant percentage increase was observed for both the diabetic animals treated with Glibenclamide (5mg/kg body weight) and Gdf Herbal mixture $(0.3 \mathrm{mg} / \mathrm{kg}$ body weight) as against a decrease in the untreated diabetic rats. The increase in the HDL level indicates a positive effect of Gdf on the lipid level as the HDL level signifies the amount of good cholesterol in the body system. Also, it might be due to the elevated activity of lecithin cholesterol acyl transferase (LCAT), which may contribute to blood lipid regulation [18]. According to the observed result, the positive activity of Gdf on the lipid profile can be attributed to two sources, Chrysophyllum albidum (White Star Apple) and Curciligo pilosa (African Crocus) which are present in the mixture, and have been identified by Adebayo et al., (2010) and Dong et al., (2013) to have an effect on lipid profile [19, 20]. Lowering total cholesterol, triglyceride and LDL-cholesterol levels of the plasma and heart tissues reduce the risk of hypercholesterolemia and hyperlipidemia that may precipitate into coronary atherosclerosis and other related cardiovascular diseases [21].

\section{Conclusion}

In conclusion, the results of the study shows that moderate consumption of Gangaria de Flush herbal mixture may be used to treat dyslipidemia or elevated lipid profile related conditions. 


\section{Compliance with ethical standards}

\section{Acknowledgments}

We hereby acknowledge the Department of Biochemistry, Babcock University, which provided the laboratory space that enabled this research to be successfully conducted.

\section{Disclosure of conflict of interest}

There is no conflict of interest amongst the authors as all the authors contributed in one way or the other in conducting the research and in writing the manuscript which was eventually articulated and submitted for publication by the corresponding author.

\section{Statement of ethical approval}

This research is in full compliance with ethical standards and was approved by Babcock University Health Research Ethics Committee.

\section{References}

[1] Davis S. Insulin, oral hypoglycemic agents and the pharmacology of the endocrine pancreas. In: Brunton L, Lazo J, Parker K. (eds.) Goodman and Gilman's the pharmacological basis of therapeutics. New York: McGraw Hill; 2006; 1613-46.

[2] Howard BV. Lipoprotein metabolism in diabetes mellitus. Journal of Lipid Research. 1987; 28: 613-628.

[3] Martim AC, Sanders RA, Watkins J. Diabetes, oxidative stress and antioxidants: a review. Journal of Biochemical Toxicology. 2003; 17: 24-38.

[4] Mutalik S, Sulochana B, Chetanam M, Udupa N, Devi VP. Preliminary studies on acute and sub-acute toxicity of an antidiabetic herbal preparation-Dianex. 2003; 41: 316-320.

[5] Noor A, Gunasekaran S, Manickam AS, Vijayalakshmi MA. Antidiabetic activity of Aloe vera and histology of organs in streptozotocin -induced diabetic rats, Current Trends in Science. 2008; 94: 1070-1076.

[6] Baily CJ, Day C. Traditional plants medicines as treatments for diabetes. Diabetes Care. 1989; 553-564.

[7] Jia W, Gao WY, Xiao PG. Antidiabetic drugs of plants origin used in china: composition, pharmacology and hypoglycemic mechanism. Zhongguo Zhong Yao Za Zh. 2003; 28: 108-113.

[8] Elder C. Ayurveda for diabetes mellitus: a review of the biomedical literature. Alternative Therapy for Health Medicine. 2004; 10: 44-50.

[9] Oreagba AI, Oshikoya AK, Amachree M. Herbal medicine use among urban residents in Lagos, Nigeria. BMC Complementary and Alternative Medicine. 2011; 11: 117.

[10] Ghule BV, Ghant MH, Saoji N, Yeole PG. Hypolipidemic and anti-hyperlipidemic effects of Lagenaria siceraria (Mol) fruit extracts. Indian Journal of Experimental Biology. 2006; 44: 905-909.

[11] Ramachandran S, Asokkumar K, Uma-Maheswari M, Ravi TK, Sivashanmugam AT, Saravanan S. Investigation of antidiabetic, antihyperlipidemic, and in vivo antioxidant properties of Sphaeranthus indicus Linn. In type 1 diabetic rats: an identification of possible biomarkers. Evidence Based Complement Alternative Medicine. 2011; 20(11): 571-721.

[12] Tanko Y, Yerima M, Mahdi MA, Yaro AH, Musa KY, Mohammed A. Hypoglycemic activity of methanolic stem bark of Adansonnia digitata extract on blood glucose levels of streptozotocin-induced diabetic Wistar rats. International Journal of Applied Research for National Production. 2008; 1: 32-36.

[13] Celeste MP, Denise AR, Anderson AS, Raimundo S.... Juliana MF, Estela Q. In vivo evaluation of the hypoglycemic effect of wolf apple flour (Solanum lycocarpum A. St-Hil). African Journal of Biotechnology. 2014; 13: 32.

[14] Chandramohan G, Ignacimuthu S, Pugalendi KV. A novel compound from Caearia esculenta (Roxb.) root and its effect on carbohydrate metabolism in streptozotocin-diabetic rats. European Journal on Pharmacology. 2008; 590: 437-443. 
[15] Sampson M, Ling C, Sun Q, Harb R, Ashmaig M, Warnick R, Sethi A, Fleming JK....Remaley AT. A New Equation for Calculation of Low-Density Lipoprotein Cholesterol in Patients with Normolipidemia and/or Hypertriglyceridemia. JAMA Cardiology. 2020; 5(5): 540-548.

[16] Papaccio G, Eposito V, Latronico MV, Pisanti FA. Administration of a nitric oxide synthase inhibitor does not suppress low-dose streptozotocin-induced diabetes in mice. International Journal of Pancreatology. 1995; 17: 63-68.

[17] Veerapur VP, Prabhakar KR, Parihar VK, Bansal P, Srinivasan KK, Priyadarsini KI, Unnikrishnan MK. Antidiabetic, hypolipidemic and antioxidant activity of Dodonaea viscos aerial parts in streptozotocin induced diabetic rats. International Journal of Phytomedicine. 2010; 2: 59-70.

[18] Patil UK, Saraf S, Dixit VK. Hypolipidemic activity of seeds of Cassia tora Linn. Journal of Ethnopharmacology. 2004; 90: 249-252.

[19] Adebayo AH, Abolaji AO, Opata TK, Adegbenro IK. Effects of ethanolic leaf extract of Chrysophyllum albidum G. on biochemical heamatological parameters of albino wister rats. African Journal of Biotechnology. 2010; 9(14).

[20] Dong X, Nie Y, He Y. Medicinal plants of genus Curculigo: traditional uses and a phytochemical and ethnopharmacological review. Journal of Ethnopharmacology. 2013; 147(3): 547-563.

[21] Witztum JL, Steinberg D. 2001. The oxidative modification hypothesis of atherosclerosis: Does it hold for humans? Trends in Cardiovascular Medicine. 2001; 11: 93-102. 